\title{
ICT Integration in FL Teacher Training
}

\author{
Kong Ying $^{1}$ Liu Xiaoling ${ }^{2}$ \\ ${ }^{1}$ Shi Jiazhuang University of Economics \\ ${ }^{2}$ Shi Jiazhuang Army Command College
}

\begin{abstract}
The presence and usage of ICT( Information and Communication Technology) have brought great changes to language learning and teaching. However, some foreign language teachers are "out-ofdate" in this new progress, which hinder the whole effect of teaching reform in china. This paper tries to propose some thought on improving ICT for FL teachers.
\end{abstract}

Keywords: FL teacher ICT course integration

\section{Introduction}

Information Technology and Teacher Education (ITTE) have brought allaround attention for foreign scholars early in the 1980s'. With the dramatic development of computer and Internet, Information and Communication Technology (ICT) are linked closely to teaching, especially language teaching in recent years in China. Teachers are thought to achieve the best teaching effects and attain quality education by presenting perceptual materials and creating a "real" communication environment.

As a result, Government and many universities put more efforts on hardware investment and software development, which lead a new trend of college English reform. Education Department also wrote it in "Curriculum Requirement of College English Teaching" (2007), Internet-based automatic learning model are prevalent in many universities in China.
While in many classes, ICT infrastructures such as multimedia classrooms and campus network are available, some teachers cannot use ICT effectively. Some teachers even are resistant to students' interest in ICT because they think "it is associated with play or the access of irrelevant or inappropriate content". Some teachers fit in well with the tradition style and felt puzzled and nervous when "studentscentered". Some teachers have a strong will to use ICT in their teaching class, but they can only use one or two kinds of technology. As a foreign language teacher, it is very important to equip with new concept and new skills, to integrate ICT to different courses, to make best use of modern science.

\section{Current Situation of ICT for For- eign Language Teachers}

In China, some scholars have paid much attention to Information accomplishment of foreign language teachers. The research (by He Gaoda2005; Fan Jiaolian 2005; Guo Qiang 2004; Ma Junbo 2003) shows that there really are some problems the quality of FL teachers when using ICT. For example, 1) They are lack of systematic theoretical knowledge; 2) They are insufficient in practical operating ability; 3) They are unfamiliar with sources of Internet and learning software. 4) They have deficiency in integration of technology to their courses. So there is a long way to go for integrating ICT into Curriculum and realizing the real modernization, 
information, networking, digitizing, intelligentizing and diversification of foreign language teaching.

So an overall analysis of ICT current situation is very helpful to us to know exactly the essence of the problem.

\subsection{Pre-service Education}

Courses on Integration of ICT are still on the edge of foreign language curriculums in many universities. Five professional courses such as TEFL pedagogy, teaching language, teaching skills etc. are set in many normal universities for foreign language students. However, due attention are demanded in CALL courses or some courses related to ICT. Besides, some computer courses such as "Fundamental Application of Computer Technology" and "Network and Education Technology" are commonly out of date, which can' t meet the need of modern education technology. While in post-graduation phrase, there are only several universities ( $\mathrm{Su}$ Zhou University, South China Normal University etc.) have CALL or corpus courses, which are still at initial and researching stage.

Recently, many universities have done a lot of work in introducing and supporting ICT, but it's a pity that foreign language teachers don't well-equipped. Also, there are rare teachers who can integrate ICT with foreign language courses. If a FL teacher can't integrate ICT well in their teaching procedures as a model, he or she can't form an atmosphere of technological culture and can't exert an edifying influence on their students. Foreign documents on CALL shows that FL teachers know what to do and how to do in pre-service education, which might have potential influence on their teaching outlook and methodology of on-job training. Actually, some young FL teachers are in embarrassment situation just after their graduation: They get into troubles when facing new information technology and when integrating technology into teaching.

\subsection{On-job Training}

Improving information literacy, receiving various ICT training to make FK teachers know software and network are important and main contents in on-job training. However, some problems appear at the same time, such as 1) On Organization, many on-job training use a single and unchanged operating pattern; 2) On Model, skill-centered "training class" and theory-centered "expert lectures" are two main models; 3) On Methods, expertscentered is prevalent while ignoring of practical operating; 4)On Contents, lacking requirement analysis and separating the close relationship between technology and teaching knowledge enhance FL teachers' anxiety and resistance. As a matter of fact, may teachers have a limited understanding of ICT theory and its benefits after a socalled "systematic training".

To sum up, while ICT becomes more and more prevalent in today's foreign language teaching. There are still a lot questions on theory and practice of ICT unsolved.

\section{Models for Development of ICT for Foreign Language Teachers}

Society for Information Technology and Teacher Education (SITE) proper in 2003 three principles on using ICT effectively: (1) ICT goes through the whole education of teachers training; (2)ICT presents through teaching situations; (3) Learners are encouraged to experience brand new information teaching environment. Jung (2005) concluded four patterns on ICT training: 


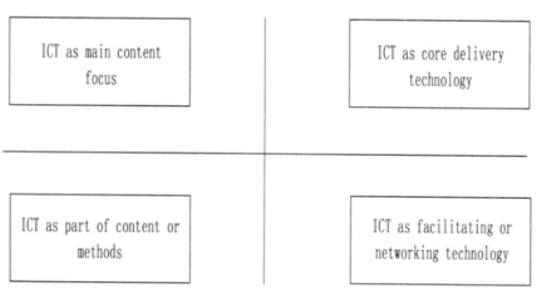

Fig 1 Four patterns on ICT Training

Jung pointed out that in the new century ICT training should transit for ICT as main content focus to ICT as integration of technology and curriculum. In the new pattern, as a teaching method and studying tool, technology goes through the whole study procedures. And learners study and master new knowledge and skills by fully experience the environment of integration. At present, in EU, ICT training for FL teachers follows the same idea, that is, making ICT as core delivery, as part of content and method or as facilitating or networking technology.

\section{Thoughts on Construction of New Models of ICT for FL Teachers}

ICT is not a goal in itself. Without a systematic integration of content and professional development for teachers, it is only a tool. There is much work to do so as to face challengers of ICT in the new trend of College English Reform.

\subsection{Construct Harmonious Atmos- phere of Technology Culture}

A harmonious social humanistic environment is basis for developing ICT training courses for FL teachers. Some excellent experience of European countries is worthy of reference: 1) establish the position and role of ICT in FL teachers' training so that ICT skill can go through the whole stages of FL teachers' career development; 2) invest more on ICT training, integrate all kinds of sources and develop on-line training program, all of which make FL teachers benefit as many as possible; 3) take advantage of academic research institutions, construct local research and provide communication study platform to enrich and perfect CALL theory and practice.

\subsection{Consider Fully the Need of Learn- ers}

High-quality requirement analysis is the basis, premise and key of successfully developing training courses. Most learners, especially FL teachers take part in the training course with their own practical problems and tasks in teaching. So they have a strong desire to have ICT learning integrated organically into their own language teachings. And thus, the most important thing is to have careful and painstaking requirement analyses, which decide the achievement of expected goals.

By communication between students and teachers, experts may know the basis character of learners' emotion, cognitive ability, ICT knowledge and levels etc. At the same time, more attention is paid to teaching experience and individual education idea. All of these factors are considered when setting up ICT teacher objects, teaching contents, teaching methods and evaluation etc. Besides, different requirements of learners can feedback to courses' developers by various effective mechanisms, such as interview, questionnaire, online forum, blog etc. It is proved that attaching importance to feedback information with necessary amendment and supplement are one of the successful factors of ICT training.

\subsection{Integrate ICT into Real Language Teaching}

ICT training of FL teachers should embody the principle of integration 
between technology and course. And thus it becomes more important to immerse ICT learning and using into a real teaching environment. Various knowledge and skills (search engines, web design, corpus etc.) are showed through the real ways (resource learning, cognitive tools, problem solving etc.). Learners know exactly the truly meaning of what they are learning, (for example, searching on-line, finding words and machine translation) and experience various new teaching concepts such as cooperative learning, autonomous learning in the atmosphere of modern information. Cradler (1997) thought, only by integrate ICT with real course can FL teachers fully understand the giant role of ICT and furthermore have the demand to attain the utmost ICT ability.

\subsection{Give Much Attention to Relevant Theory of ICT}

Solid theoretical basis is the premise of using any new skills scientifically and rationally. CALL has the character of Interdisciplinary, which includes linguistic, sociology, psychology, cognition and culture research. As a result, the ICT training of FL teachers is not a simple technical question but an education question, which needs some relevant theories to support. The theoretical basis of ICT includes basic concepts, historical development, tendency analyses, conceptual frameworks, pedagogy and evaluation etc. In fact, as a subject with wide application, most documents or papers on CALL are theory-and-practice-related. Therefore, by a great deal of documents' reading and researching, FL teachers can not only have strong theoretical basis but also are beneficial for widening teaching horizon, which may be helpful to the development of their whole teaching carrier.

\section{Conclusion}

ICT is an effective way for distributing educational materials to students. There is a growing trend that universities are using the Internet to support teaching and learning. In a sense, ICT is changing foreign language teaching in universities in all aspects. So how to integrate ICT organically into foreign language teaching and to promote teaching and learning indeed are issues that all foreign language education researchers and scholars must take into a serious consideration.

First use the equation editor to create the equation. Then select the "Equation" markup style.

\section{References}

[1] Cradler J. Implementing technology in education: Recent findings from research and evaluation studies [J/OL].http://www.fwl.org/techpolicy /recapproach.html 1997. Accessed 10 Oct. 2005.

[2] Jung I. ICT-Pedagogy integration in teacher training: Application cases [J].Educational Technology\& Society, 2005, 8, (2): 94-101.

[3] Wu Zunmin. Pre-service English Language Teacher Education in China) BA/TEFL Curriculum Studies [R].BNU Centenary International Conference on English Teacher Education and Development, 2002.asp. 